\title{
Textural and Eye Qualities of Injera Prepared from Quality Protein Maize and Teff Blended Flours
}

\author{
Umer Asrat Yasin \\ Food Science and Nutrition Research Directorate, Melkassa Agricultural Research Center, Ethiopian Institute of Agricultural Research, \\ Melkassa, Ethiopia
}

Email address:

umerasrat88@gmail.com

\section{To cite this article:}

Umer Asrat Yasin. Textural and Eye Qualities of Injera Prepared from Quality Protein Maize and Teff Blended Flours. International Journal of Nutrition and Food Sciences. Vol. 10, No. 4, 2021, pp. 78-85. doi: 10.11648/j.ijnfs.20211004.11

Received: May 18, 2021; Accepted: July 5, 2021; Published: July 13, 2021

\begin{abstract}
Injera is fermented, leavened, flat and round pancake-like Ethiopian traditional bread, and made from cereals like teff, wheat, barley, sorghum, maize or a combination of some of these cereals. This study was conducted to investigate the effect of blending ratio and fermentation times on the textural and eye /hole/ characteristics of injera prepared from quality protein maize (QPM) and teff composite flours. Factorial design of two factors in CRD arrangement was used. The factors were blending ratio of teff flour $(20 \%, 30 \%$, and $40 \%)$ and fermentation times $(48 \mathrm{hr}, 60 \mathrm{hr}$, and $72 \mathrm{hr})$. The sensory acceptability scores for eye-size, texture, and rollability were ranged from 5.08 to $5.50,5.01$ to 5.76 , and 4.61 to 5.69 due to blending ratio, respectively and from 5.18 to $5.41,5.28$ to 5.48 , and 5.08 to 5.29 due to fermentation times, respectively tested for fresh injera. The peak force, which indicate the firmness level of injera samples also varied significantly $(\mathrm{p}<0.05)$ and the values ranged between 2.23 to $3.13 \mathrm{~N}$ (first day) due to blending ratio and from 2.59 to $2.69 \mathrm{~N}$ (first day) due to fermentation times. Increasing the blending proportions of teff flour in the composite was found improving the texture, firmness, and eye qualities of QPM-teff composite injera samples.
\end{abstract}

Keywords: Quality Protein Maize, Teff, Injera, Texture, Firmness

\section{Introduction}

Native to Ethiopia and Eritrea, injera is a traditional sourdough flatbread with teff as a major ingredient [7]. However, depending on the agroecology of the area concerned different cereals (sorghum, wheat, finger millet, maize, and barley) and their blends are used to make injera $[11,5]$. A good injera is soft, fluffy, and able to be rolled without cracking. It should retain these textural properties after 2 to 3 days of storage. Injera made from teff is most preferred due to its softer texture, preferred taste, its color and can be rolled without cracking. The front side of a good quality injera has uniformly spaced honeycomb-like pores traditionally called "eyes", formed due to the penetration of escaping gas that is produced during fermentation and baking, whereas the bottom surface of injera is smooth and shiny [10].

Injera prepared from quality protein maize are only preferred in their fresh state and softness does not last as long as teff injera. Upon storage, it firms rapidly and becomes friable. Because of this, the use of quality protein maize for injera making received little attention [13]. Quality protein maize (QPM) is nutritionally enhanced maize developed through conventional breeding method. It contains nearly twice the quantity of lysine $(>4.0 \%)$ and tryptophan $(>0.8 \%)$ present in the conventional maize $[6,8,12]$. Increasing the consumption of food products prepared from QPM is the ideal solution to problems related to malnutrition [13]. Therefore, the study planned to improve textural, rollability, and firmness qualities of injera prepared from quality protein maize flour through compositing with teff flour and identifying the fermentation time required to maximize the utilization of QPM by the consumers in the country.

\section{Materials and Methods}

\subsection{Flour Preparations}

Quality protein maize (Melkassa-6Q) and teff (Magna) grains were collected from Melkassa Agricultural Research Center and Debre Zeit Agricultural Research Center of Ethiopian Institute of Agricultural Research, respectively. The grains were sorted and cleaned, and separately milled 
(UDY3010-019, USA) to a sieve size of $0.50 \mathrm{~mm}[13]$.

\subsection{Injera Making}

About $200 \mathrm{~g}$ of flour was mixed with $180 \mathrm{ml}$ of water and kneaded for 2 mins. Then, $10 \mathrm{ml}$ of ( $5 \%$ on flour weight basis) pre-prepared starter yeast (irsho) was poured on the dough and left to ferment for 48,60 , and $72 \mathrm{hrs}$ at room temperature. After the primary fermentation, about $10 \%$ of the fermented dough was taken and mixed with three parts of boiling water and then mixed thoroughly for $1 \mathrm{~min}$ (absit). The mixture was left at room temperature until the temperature dropped and then, the mixture was added back on the fermenting dough and mixed well. To this, $100 \mathrm{ml}$ of water was added and the mixture was let to ferment for about $3-4 \mathrm{hrs}$ at room temperature until a foamy slurry was formed. Then, the slurry was poured on an electric clay stove in circular motions and covered to cook for 2 mins [14].

\subsection{Sensory Evaluation}

Sensory evaluation of injera samples were carried out by 30 panelists composed of male and female. The evaluation was carried out for freshly baked injera, on the second and third days, respectively. The panelists were requested to test the injera samples in terms of eye-size, texture, and rollability using sevenpoint hedonic scale ( $1=$ dislike extremely, $2=$ dislike moderately, $3=$ dislike slightly, $4=$ =either like nor dislike, $5=$ like slightly, $6=$ like moderately, and 7=like extremely) [16].

\subsection{Firmness Test}

The firmness of the injera samples were measured following the procedure described by Senayit et al. with slight modification [10]. The peak force was determined using texture analyzer (TA.XT plus, Stable Micro Systems, Godalming, UK) in a compression mode with a sharp blade cutting probe and TA90 heavy duty platform. The settings were: pre-test speed 4.0 $\mathrm{mm} / \mathrm{s}$, test speed $2.0 \mathrm{~mm} / \mathrm{s}$, post-test speed $\sim 5 \mathrm{~mm} / \mathrm{s}$, distance $3.5 \mathrm{~mm}$, load cell $\sim 5 \mathrm{~kg}$, and operating software (Exponent, version 5.1.10). The firmness was measured for freshly baked injera, on the second and third days, respectively.

\subsection{Determination of Number of Eyes and Color}

The number of eyes on the surface of injera and color (surface and hole) were determined using software (InjeraEyes, version 1.0.0.0). Photo images were taken for each injera samples using digital color camera form similar height and with uniform light intensity. Then, to fit the software, the image of injera samples were cropped into 1550 pixels by 1550 pixels (width by height) $[1,13]$.

\subsection{Experimental Design and Analysis}

The experiment was carried out in triplicates for all the measured parameters. A factorial design of two factors in completely randomized design arrangement was used. The factors were blending ratio of teff flour $(20,30$, and $40 \%)$ and fermentation time (48, 60, and $72 \mathrm{hrs})$. The experimental data was statistically analyzed using SAS software (version 9.4) following PROC ANOVA procedure. Means were separated by Fisher's least significant difference (LSD) test at $p<0.05$ level of significance. The results were expressed as mean \pm standard deviation.

\section{Results and Discussions}

\subsection{Eye-Size and Textural Qualities of QPM-teff Blended Injera}

The results for eye-size, texture, and rollability scores of QPM-teff composite injera samples are presented in Table 1. The mean scores for eye-size ranged from $5.08-5.50$, and blending ratio had significant effect $(\mathrm{p}<0.05)$. The eye-size of injera prepared from composite flour ratio of $60 \%$ QPM and $40 \%$ teff obtained the highest score and injera prepared from QPM $(100 \%)$ flour obtained the lowest score. Fermentation times also had significant effect $(p<0.05)$ on the eye-size and the mean scores ranged from $5.18-5.41$. The number of eyes and the distribution on the surface of injera is a good indicator of injera quality. Ideally, eyes should neither be too few nor too numerous, they must be rather deep, interlocked with thin cross walls between them and be evenly distributed [11].

Table 1. Eye-size and textural qualities of QPM-teff blended injera.

\begin{tabular}{|c|c|c|c|c|c|c|c|}
\hline \multirow{2}{*}{ Blending ratio (\%) } & \multirow{2}{*}{ Eye-size } & \multicolumn{2}{|l|}{ First day } & \multicolumn{2}{|l|}{ Second day } & \multicolumn{2}{|l|}{ Third day } \\
\hline & & Texture & Rollability & Texture & Rollability & Texture & Rollability \\
\hline 100: 0 & $5.08 \pm 0.86^{\mathrm{c}}$ & $5.01 \pm 0.86^{\mathrm{d}}$ & $4.61 \pm 1.17^{\mathrm{d}}$ & $4.53 \pm 0.93^{\mathrm{d}}$ & $4.59 \pm 1.13^{\mathrm{d}}$ & $4.34 \pm 0.81^{\mathrm{d}}$ & $4.27 \pm 1.04^{\mathrm{c}}$ \\
\hline 80: 20 & $5.20 \pm 0.94^{\mathrm{bc}}$ & $5.24 \pm 0.64^{\mathrm{c}}$ & $4.94 \pm 0.81^{\mathrm{c}}$ & $4.94 \pm 0.81^{\mathrm{c}}$ & $4.88 \pm 0.95^{\mathrm{c}}$ & $4.79 \pm 0.94^{\mathrm{c}}$ & $4.62 \pm 1.01^{\mathrm{b}}$ \\
\hline 60: 40 & $5.50 \pm 0.78^{\mathrm{a}}$ & $5.76 \pm 0.72^{\mathrm{a}}$ & $5.69 \pm 0.71^{\mathrm{a}}$ & $5.58 \pm 0.78^{\mathrm{a}}$ & $5.57 \pm 0.78^{\mathrm{a}}$ & $5.40 \pm 0.91^{\mathrm{a}}$ & $4.97 \pm 1.12^{\mathrm{a}}$ \\
\hline $\mathrm{CV}(\%)$ & 15.00 & 12.80 & 15.11 & 13.06 & 15.88 & 15.42 & 20.30 \\
\hline LSD & 0.23 & 0.20 & 0.23 & 0.20 & 0.24 & 0.22 & 0.28 \\
\hline \multirow{2}{*}{ Fermentation time (hrs) } & \multirow{2}{*}{ Eye-size } & \multicolumn{2}{|l|}{ First day } & \multicolumn{2}{|l|}{ Second day } & \multicolumn{2}{|l|}{ Third day } \\
\hline & & Texture & Rollability & Texture & Rollability & Texture & Rollability \\
\hline 48 & $5.27 \pm 0.76^{\mathrm{ab}}$ & $5.28 \pm 0.76^{\mathrm{b}}$ & $5.08 \pm 0.82^{\mathrm{b}}$ & $5.00 \pm 0.82^{\mathrm{b}}$ & $5.02 \pm 0.87^{\mathrm{a}}$ & $4.73 \pm 0.98^{b}$ & $4.53 \pm 1.01^{\mathrm{b}}$ \\
\hline 60 & $5.41 \pm 0.88^{\mathrm{a}}$ & $5.35 \pm 0.82^{\mathrm{ab}}$ & $5.16 \pm 1.14^{\mathrm{ab}}$ & $5.08 \pm 0.94^{\mathrm{ab}}$ & $5.06 \pm 1.10^{\mathrm{a}}$ & $5.00 \pm 0.90^{\mathrm{a}}$ & $4.64 \pm 1.17^{\mathrm{ab}}$ \\
\hline 72 & $5.18 \pm 0.90^{\mathrm{b}}$ & $5.48 \pm 0.77^{\mathrm{a}}$ & $5.29 \pm 0.92^{\mathrm{a}}$ & $5.24 \pm 0.93^{\mathrm{a}}$ & $5.18 \pm 0.98^{\mathrm{a}}$ & $5.06 \pm 0.99^{\mathrm{a}}$ & $4.83 \pm 1.00^{\mathrm{a}}$ \\
\hline CV (\%) & 15.00 & 12.80 & 15.11 & 13.06 & 15.88 & 15.42 & 20.30 \\
\hline LSD & 0.20 & 0.17 & 0.20 & 0.17 & 0.21 & 0.19 & 0.24 \\
\hline
\end{tabular}

Data: mean $\pm \mathrm{SD}$, means with the same letter in the column are not significantly different, QPM flour $=60,70$, and $80 \%$, teff flour $=20,30$, and $40 \%$. 
The texture acceptability of injera samples were significantly influenced $(p<0.05)$ by blending ratio and fermentation times. The scores ranged between 5.01 to 5.76 , 4.53 to 5.58 , and 4.34 to 5.40 due to blending ratio and ranged between $5.28-5.48,5.00-5.24$, and $4.73-5.06$ due to fermentation times for the first, second, and third days, respectively. Injera samples prepared from QPM (100\%) flour and QPM-teff composite flour (80: 20) were rated below 5 in the second and third days, and the response indicated lower degree of liking compared to injera samples having 30 and $40 \%$ teff flour. Textural properties are key drivers in food acceptability. Previous work of Senayit et al. reported that teff injera is relatively soft compared to sorghum injera [10]. The work of Zewdu et al. also reported that an increasing trend of liking the texture of teff-ricemaize composite injera when the proportion of teff and rice are increased, and texture score decreased when the proportion of maize is increased [16]. The relative softness of teff injera could be related to starch granule size. Teff starch have smaller granule size $(2-6 \mu \mathrm{m})$ compared with maize $(20 \mu \mathrm{m})$ and sorghum $(20 \mu \mathrm{m})$ starch granule sizes [2].

The rollability of injera samples significantly influenced $(p<0.05)$ by blending ratio of teff flour and fermentation times. The mean scores varied from 4.61 to $5.69,4.59$ to 5.57 , and 4.27 to 4.97 due to blending ratio for the first, second and third days, respectively. Only injera samples prepared from QPM-teff composite flour ratio of 70: 30 and 60: 40 (QPM: teff) were liked in the first and second days and the other injera samples were rated below 5 , and they were not liked by the panelists.

\subsection{Effect of Blending Ratio and Fermentation Time on Firmness of QPM-teff Blended Injera}

Table 2 indicates the firmness of QPM-teff composite injera samples tested in the first, second and third days. Blending ratio significantly affected $(\mathrm{p}<0.05)$ the firmness of the samples and the values ranged from 2.23 to $3.13 \mathrm{~N}$. The highest peak force was recorded for QPM $(100 \%)$ injera and the lowest peak force was recorded for QPM-teff composite injera (60: 40). As the fermentation time varied from 48 to 60 , and $72 \mathrm{hrs}$, maximum force values of $2.69,2.65$, and $2.59 \mathrm{~N}$ were also recorded, respectively. Peak force values ranged from 2.35 to $3.24 \mathrm{~N}$, and $2.46-3.37 \mathrm{~N}$ were also recorded in the second and third days due to blending ratio. The values were greater than the peak force required for cutting teff injera $(2.01,2.12$, and $2.23 \mathrm{~N})$. From the result it was observed that, as the level of teff flour increased in the composite, the force required for cutting (injera) decreased. It has been reported that the hardness that develops in starchbased products during storage is due to the retrogradation of starch molecules [3]. Onyango et al. reported that, bread prepared from wheat-maize composite flour having higher proportion of maize flour required the maximum force of cutting [9]. The authors recorded the peak force values of $1.27,1.52,2.68$, and $7.62 \mathrm{~N}$ for bread samples prepared from the wheat-maize composite flour ratio of 100: 0, 90: 10, 80:
20, and 70: 30 , respectively.

Table 2. Effect of blending ratio and fermentation time on firmness of QPMteff blended injera.

\begin{tabular}{|c|c|c|c|}
\hline $\begin{array}{l}\text { Blending ratio } \\
(\%)\end{array}$ & First day (N) & Second day (N) & Third day (N) \\
\hline 100: 0 & $3.13 \pm 0.04^{\mathrm{a}}$ & $3.24 \pm 0.08^{\mathrm{a}}$ & $3.37 \pm 0.08^{\mathrm{a}}$ \\
\hline 80: 20 & $2.70 \pm 0.07^{b}$ & $2.81 \pm 0.07^{b}$ & $2.97 \pm 0.09^{b}$ \\
\hline $70: 30$ & $2.49 \pm 0.09^{c}$ & $2.60 \pm 0.11^{\mathrm{c}}$ & $2.73 \pm 0.09^{c}$ \\
\hline 60: 40 & $2.23 \pm 0.13^{\mathrm{d}}$ & $2.35 \pm 0.08^{\mathrm{d}}$ & $2.46 \pm 0.10^{\mathrm{d}}$ \\
\hline CV $(\%)$ & 1.99 & 1.52 & 1.61 \\
\hline LSD & 0.05 & 0.04 & 0.05 \\
\hline $\begin{array}{l}\text { Fermentation } \\
\text { time (hrs) }\end{array}$ & First day & Second day & Third day \\
\hline 48 & $2.69 \pm 0.35^{\mathrm{a}}$ & $2.82 \pm 0.35^{\mathrm{a}}$ & $2.94 \pm 0.35^{\mathrm{a}}$ \\
\hline 60 & $2.65 \pm 0.36^{\mathrm{a}}$ & $2.73 \pm 0.34^{\mathrm{b}}$ & $2.88 \pm 0.36^{\mathrm{b}}$ \\
\hline 72 & $2.59 \pm 0.35^{\mathrm{b}}$ & $2.70 \pm 0.34^{\mathrm{b}}$ & $2.82 \pm 0.36^{\mathrm{c}}$ \\
\hline CV $(\%)$ & 1.99 & 1.52 & 1.61 \\
\hline LSD & 0.04 & 0.04 & 0.04 \\
\hline Teff injera & $2.01 \pm 0.07$ & $2.12 \pm 0.08$ & $2.25 \pm 0.07$ \\
\hline
\end{tabular}

Data: mean $\pm \mathrm{SD}$, means with the same letter in the column are not significantly different, QPM flour $=60,70$, and $80 \%$, teff flour $=20,30$, and $40 \%, \mathrm{~N}=$ Newton.

\subsection{Interaction Effects of Blending Ratio and Fermentation Time on Firmness of QPM-teff Blended Injera}

Table 3 shows the interaction effects of blending ratio and fermentation time on the firmness of QPM-teff composite injera. The highest values $(3.16,3.31$, and $3.42 \mathrm{~N})$ were recorded for injera sample prepared from QPM (100\%) flour and the lowest values $(2.19,2.30$, and $2.41 \mathrm{~N})$ were recorded for injera sample prepared from QPM-teff composite flour (60: 40). Texture analysis is primarily concerned with the evaluation of mechanical characteristics where a material is subjected to controlled force from which deformation curve of its response is generated [9].

\subsection{Effect of Blending Ratio and Fermentation Time on the Number of Eyes and Color of QPM-teff Blended Injera}

The number of eyes and color of QPM-teff composite injera samples are presented in Table 4. Blending ratio had significant effect $(p<0.05)$ on the number of eyes and the values ranged from 3618.22 to 6847.89 . The highest value was recorded for injera sample prepared from QPM-teff composite flour having $30 \%$ teff, followed by $20 \%$ teff and the lowest value was recorded for injera sample prepared from QPM (100\%) flour. Fermentation time also had significant $(\mathrm{p}<0.05)$ effect on the number of eyes and values of 5310.42, 5412.17, and 6542.92 were recorded from injera samples fermented for 48,60 and 72 hrs, respectively. The number, size and distribution of holes; commonly called eyes on the injera surface represent one of the most important qualities attributes of injera [11]. Hayelom reported the number of eyes of teff injera ranged from 17764.50 to 19609.20 (area not specified) for injera samples prepared from different teff varieties [4]. Yoseph also reported the number of eyes of teff injera varied from 224 to 298 
(unspecified area) for injera samples prepared from teff flour milled by different millers [15].

Blending ratio and fermentation time had significant effect $(\mathrm{p}<0.05)$ on the color of injera samples. The lightness $\left(\mathrm{L}^{*}\right)$ values ranged from 64.66 to 70.32 . Injera samples prepared from QPM (100\%) and QPM-teff composite flour (80: 20) obtained the highest $\mathrm{L}^{*}$ value and had no significant difference $(\mathrm{p}>0.05)$. The lowest $\mathrm{L}^{*}$ value was recorded from injera sample prepared from $60 \%$ QPM and $40 \%$ teff composite flour. The work of Zewdu et al. also reported that, the $\mathrm{L}^{*}$ value of teff injera (54.65) was lower than the $\mathrm{L}^{*}$ value of injera (63.17) prepared from teff-maize-rice composite (70: 0: 30) flour [16]. The redness $\left(\mathrm{a}^{*}\right)$ values of QPM-teff composite injera were varied from $0.92-3.81$, and $2.18-2.61$ due to blending ratio and fermentation time, and significant differences $(p<0.05)$ were noted. Higher $\mathrm{a}^{*}$ value was recorded for injera sample prepared from QPM-teff composite flour having $40 \%$ teff and lower value was recorded for injera sample prepared from QPM (100\%) flour. Injera sample fermented for $48 \mathrm{hrs}$ showed the highest $a^{*}$ value whereas those fermented for 72 hrs showed the lowest $a^{*}$ value.

The yellowness $\left(b^{*}\right)$ values of QPM-teff composite injera varied significantly $(\mathrm{p}<0.05)$ from 5.06 to 13.24 due to blending ratio, and from 9.18 to 11.00 due to fermentation time. As the blending ratio of teff flour increased $(20,30$, and $40 \%)$ in the composite, $b^{*}$ values were found increase in parallel, in contrast as the fermentation time $(48,60$, and $72 \mathrm{hrs})$ increased $b^{*}$ values were found decreasing. Significant differences $(\mathrm{p}<0.05)$ were also observed on the hole color of QPM-teff composite injera samples due to blending ratio and the values ranged from $41.53-48.01\left(\mathrm{~L}^{*}\right), 1.52-5.44\left(\mathrm{a}^{*}\right)$, and $9.11-$ $16.09\left(b^{*}\right)$. As blending ratio of teff flour increased in the blends, the lightness of the hole was found decreasing whereas the redness and yellowness values were found increasing. The fermentation time also significantly $(\mathrm{p}<0.05)$ increased the $\mathrm{L}^{*}$ values from 42.17 to 44.41 , but decreased the redness (3.87 $4.28)$ and yellowness (13.21 - 14.95) values.

Table 3. Interaction effects of blending ratio and fermentation time on firmness of QPM-teff blended injera.

\begin{tabular}{|c|c|c|c|c|}
\hline Blending ratio (\%) & Fermentation time (hrs) & First day (N) & Second day (N) & Third day $(\mathrm{N})$ \\
\hline 100: 0 & 48 & $3.16 \pm 0.03^{\mathrm{a}}$ & $3.31 \pm 0.07^{\mathrm{a}}$ & $3.42 \pm 0.08^{\mathrm{a}}$ \\
\hline 100: 0 & 60 & $3.14 \pm 0.03^{\mathrm{a}}$ & $3.20 \pm 0.07^{\mathrm{b}}$ & $3.37 \pm 0.10^{\mathrm{ab}}$ \\
\hline 100: 0 & 72 & $3.09 \pm 0.03^{\mathrm{a}}$ & $3.18 \pm 0.06^{\mathrm{b}}$ & $3.34 \pm 0.06^{\mathrm{c}}$ \\
\hline $80: 20$ & 48 & $2.78 \pm 0.05^{\mathrm{b}}$ & $2.88 \pm 0.01^{\mathrm{c}}$ & $3.03 \pm 0.07^{\mathrm{c}}$ \\
\hline $80: 20$ & 60 & $2.71 \pm 0.07^{\mathrm{bc}}$ & $2.80 \pm 0.08^{\mathrm{d}}$ & $2.98 \pm 0.10^{\mathrm{c}}$ \\
\hline 80: 20 & 72 & $2.65 \pm 0.04^{c}$ & $2.76 \pm 0.06^{\mathrm{d}}$ & $2.89 \pm 0.05^{\mathrm{d}}$ \\
\hline $70: 30$ & 48 & $2.53 \pm 0.10^{\mathrm{d}}$ & $2.66 \pm 0.10^{\mathrm{e}}$ & $2.80 \pm 0.08^{\mathrm{e}}$ \\
\hline 70: 30 & 72 & $2.43 \pm 0.05^{\mathrm{e}}$ & $2.56 \pm 0.10^{\mathrm{f}}$ & $2.64 \pm 0.05^{\mathrm{f}}$ \\
\hline 60: 40 & 48 & $2.28 \pm 0.16^{\mathrm{f}}$ & $2.41 \pm 0.07^{\mathrm{g}}$ & $2.53 \pm 0.16^{\mathrm{g}}$ \\
\hline 60: 40 & 60 & $2.23 \pm 0.14^{\mathrm{f}}$ & $2.34 \pm 0.08^{\text {gh }}$ & $2.45 \pm 0.07^{\text {gh }}$ \\
\hline 60: 40 & 72 & $2.19 \pm 0.12^{\mathrm{f}}$ & $2.30 \pm 0.08^{\mathrm{h}}$ & $2.41 \pm 0.03^{\mathrm{h}}$ \\
\hline $\mathrm{CV}(\%)$ & & 1.99 & 1.52 & 1.61 \\
\hline LSD & & 0.09 & 0.07 & 0.08 \\
\hline
\end{tabular}

Data: mean $\pm \mathrm{SD}$, means with the same letter in the column are not significantly different, QPM flour $=60,70$, and $80 \%$, teff flour $=20$, 30 , and $40 \%$, $\mathrm{N}=$ Newton.

Table 4. Effect of blending ratio and fermentation time on number of eyes and color of QPM-teff blended injera.

\begin{tabular}{|c|c|c|c|c|c|c|c|}
\hline \multirow{2}{*}{ Blending ratio (\%) } & \multirow{2}{*}{ Number of eyes } & \multicolumn{3}{|c|}{ Surface color } & \multicolumn{3}{|l|}{ Hole color } \\
\hline & & $\mathbf{L}^{*}$ & $a^{*}$ & $\mathbf{b}^{*}$ & $\mathbf{L}^{*}$ & $a^{*}$ & $\mathbf{b}^{*}$ \\
\hline 100: 0 & $3618.22 \pm 538.76^{d}$ & $70.32 \pm 0.98^{\mathrm{a}}$ & $0.92 \pm 0.19^{\mathrm{d}}$ & $5.06 \pm 0.32^{\mathrm{d}}$ & $48.01 \pm 0.32^{\mathrm{a}}$ & $1.52 \pm 0.42^{\mathrm{c}}$ & $9.11 \pm 0.82^{b}$ \\
\hline $80: 20$ & $6359.00 \pm 604.13^{b}$ & $70.09 \pm 0.89^{\mathrm{a}}$ & $1.57 \pm 0.17^{\mathrm{c}}$ & $10.70 \pm 0.40^{\mathrm{c}}$ & $42.56 \pm 0.39^{b}$ & $4.32 \pm 0.48^{\mathrm{b}}$ & $15.89 \pm 0.65^{\mathrm{a}}$ \\
\hline 70: 30 & $6847.89 \pm 632.50^{\mathrm{a}}$ & $65.61 \pm 0.84^{\mathrm{b}}$ & $3.30 \pm 0.11^{\mathrm{b}}$ & $11.97 \pm 0.44^{\mathrm{b}}$ & $42.13 \pm 0.49^{b}$ & $5.28 \pm 0.53^{\mathrm{a}}$ & $16.07 \pm 0.48^{\mathrm{a}}$ \\
\hline 60: 40 & $6195.56 \pm 595.56^{\mathrm{c}}$ & $64.66 \pm 0.93^{c}$ & $3.81 \pm 0.13^{\mathrm{a}}$ & $13.24 \pm 0.33^{\mathrm{a}}$ & $41.53 \pm 0.41^{\mathrm{c}}$ & $5.44 \pm 0.59^{\mathrm{a}}$ & $16.09 \pm 0.89^{\mathrm{a}}$ \\
\hline CV (\%) & 0.67 & 0.55 & 8.26 & 2.50 & 1.06 & 4.79 & 2.78 \\
\hline LSD & 37.52 & 0.36 & 0.19 & 0.25 & 0.44 & 0.19 & 0.39 \\
\hline
\end{tabular}

\begin{tabular}{|c|c|c|c|c|c|c|c|}
\hline \multirow{2}{*}{$\begin{array}{l}\text { Fermentation time } \\
\text { (hrs) }\end{array}$} & \multirow{2}{*}{ Number of eyes } & \multicolumn{3}{|l|}{ Surface color } & \multicolumn{3}{|l|}{ Hole color } \\
\hline & & $\mathbf{L}^{*}$ & $a^{*}$ & $\mathbf{b}^{*}$ & $\mathbf{L}^{*}$ & $a^{*}$ & $\mathbf{b}^{*}$ \\
\hline 48 & $5310.42 \pm 771.06^{\mathrm{c}}$ & $66.91 \pm 3.51^{\mathrm{c}}$ & $2.61 \pm 1.49^{\mathrm{a}}$ & $11.00 \pm 4.06^{\mathrm{a}}$ & $42.17 \pm 2.51^{\mathrm{b}}$ & $4.28 \pm 1.57^{\mathrm{a}}$ & $14.95 \pm 3.18^{\mathrm{a}}$ \\
\hline 60 & $5412.17 \pm 834.02^{b}$ & $67.63 \pm 2.74^{\mathrm{b}}$ & $2.41 \pm 1.23^{b}$ & $10.55 \pm 3.50^{\mathrm{b}}$ & $44.10 \pm 2.67^{\mathrm{a}}$ & $4.27 \pm 1.58^{\mathrm{a}}$ & $14.69 \pm 3.40^{\mathrm{a}}$ \\
\hline 72 & $6542.92 \pm 775.25^{\mathrm{a}}$ & $68.45 \pm 2.87^{\mathrm{a}}$ & $2.18 \pm 1.11^{\mathrm{c}}$ & $9.18 \pm 3.42^{\mathrm{c}}$ & $44.41 \pm 2.50^{\mathrm{a}}$ & $3.87 \pm 1.39^{c}$ & $13.21 \pm 3.23^{b}$ \\
\hline CV (\%) & 0.67 & 0.55 & 8.26 & 2.50 & 1.06 & 4.79 & 2.78 \\
\hline LSD & 32.50 & 0.31 & 0.17 & 0.22 & 0.38 & 0.17 & 0.34 \\
\hline
\end{tabular}

Data: mean $\pm \mathrm{SD}$, means with the same letter in the column are not significantly different, QPM flour $=60,70$ and $80 \%$, teff flour $=20,30$ and $40 \%$, $\mathrm{L}^{*}=$ lightness, $\mathrm{a}^{*}=$ redness, $\mathrm{b}^{*}=$ yellowness. 


\subsection{Interaction Effects of Blending Ratio and Fermentation Time on Number of Eyes and Color of QPM-teff Blended Injera}

The interaction effects of blending ratio and fermentation time on the number of eyes and color of QPM-teff blended injera are shown in Table 5. The number of eyes of injera samples ranged from 3103.33 - 7775.67, and significant differences $(\mathrm{p}<0.05)$ were observed. The maximum numbers of eyes were recorded for injera sample prepared from QPMteff composite flour (60: 40) fermented for $72 \mathrm{hrs}$ and the values were lower than teff injera (9488.33). The minimum value was recorded for injera sample prepared from QPM $(100 \%)$ flour fermented for $72 \mathrm{hrs}$. As the fermentation time extended from 48 to $72 \mathrm{hrs}$ for preparing QPM (100\%) injera, the number of eyes was found deceasing. The interaction effect of blending ratio and fermentation time on the lightness (surface) of injera was significant $(\mathrm{p}<0.05)$ and the values ranged from $62.64-70.38$.
Injera prepared from QPM (100\%) flour and QPM-teff composite flour (80:20) and fermented for 48, 60, and $70 \mathrm{hrs}$ were statistically similar $(\mathrm{p}>0.05)$. Similarly, the redness of injera samples due to the interactions of blending ratio and fermentation time was significant $(\mathrm{p}<0.05)$ and the values varied from $0.87-4.10$. Injera samples prepared from QPMteff composite flour having 30 and $40 \%$ teff, when fermented for 48 and $60 \mathrm{hrs}$ compared to $72 \mathrm{hrs}$ showed higher a* values. The yellowness of injera samples were varied significantly $(p<0.05)$ from 4.87 to 15.48 due to the interactions of blending ratio and fermentation time. Injera samples having 30 and $40 \%$ teff flour in the composite and fermented for 48 and $60 \mathrm{hrs}$ showed higher $\mathrm{b}^{*}$ values. The interaction effect of blending ratio and fermentation time on the hole color of QPM-teff composite injera was significant $(\mathrm{p}<0.05)$ and the values ranged between $48.22-39.37\left(\mathrm{~L}^{*}\right)$, $1.01-7.25\left(\mathrm{a}^{*}\right)$, and $8.26-17.50\left(\mathrm{~b}^{*}\right)$.

Table 5. Interaction effects of blending ratio and fermentation time on number of eyes and color of QPM-teff blended injera.

\begin{tabular}{|c|c|c|c|c|c|c|c|c|}
\hline \multirow{2}{*}{$\begin{array}{l}\text { Blending } \\
\text { ratio (\%) }\end{array}$} & \multirow{2}{*}{$\begin{array}{l}\text { Fermentation } \\
\text { time (hrs) }\end{array}$} & \multirow{2}{*}{ Number of eyes } & \multicolumn{3}{|l|}{ Surface color } & \multicolumn{3}{|l|}{ Hole color } \\
\hline & & & $\mathbf{L}^{*}$ & $\mathbf{a}^{*}$ & $\mathbf{b}^{*}$ & $\mathbf{L}^{*}$ & $\mathbf{a}^{*}$ & $\mathbf{b}^{*}$ \\
\hline 100: 0 & 48 & $4309.33 \pm 15.50^{j}$ & $70.25 \pm 0.16^{\mathrm{a}}$ & $0.95 \pm 0.18^{f}$ & $4.87 \pm 0.35^{\mathrm{g}}$ & $47.79 \pm 0.27^{\mathrm{a}}$ & $1.01 \pm 0.09^{\mathrm{i}}$ & $9.86 \pm 0.37^{\mathrm{f}}$ \\
\hline 100: 0 & 60 & $3442.00 \pm 18.89^{\mathrm{k}}$ & $70.32 \pm 0.16^{\mathrm{a}}$ & $0.93 \pm 0.18^{f}$ & $5.11 \pm 0.28^{\mathrm{g}}$ & $48.03 \pm 0.33^{\mathrm{a}}$ & $1.72 \pm 0.30^{\mathrm{h}}$ & $9.20 \pm 0.71^{\mathrm{f}}$ \\
\hline $80: 20$ & 48 & $5312.67 \pm 19.81^{\mathrm{h}}$ & $70.09 \pm 0.10^{\mathrm{a}}$ & $1.47 \pm 0.18^{\mathrm{e}}$ & $11.03 \pm 0.30^{\mathrm{d}}$ & $41.57 \pm 0.51^{\mathrm{ef}}$ & $2.93 \pm 0.11^{\mathrm{g}}$ & $15.49 \pm 0.27^{\mathrm{c}}$ \\
\hline 80: 20 & 60 & $6160.67 \pm 18.33^{f}$ & $70.08 \pm 0.11^{\mathrm{a}}$ & $1.61 \pm 0.13^{\mathrm{e}}$ & $10.70 \pm 0.29^{\mathrm{de}}$ & $44.25 \pm 0.55^{\mathrm{b}}$ & $4.79 \pm 0.27^{\mathrm{e}}$ & $15.47 \pm 0.17^{\mathrm{c}}$ \\
\hline 80: 20 & 72 & $7603.67 \pm 14.84^{c}$ & $70.07 \pm 0.13^{\mathrm{a}}$ & $1.63 \pm 0.22^{\mathrm{e}}$ & $10.36 \pm 0.34^{\mathrm{ef}}$ & $41.87 \pm 0.81^{\mathrm{e}}$ & $5.25 \pm 0.16^{\mathrm{cd}}$ & $16.70 \pm 0.44^{\mathrm{b}}$ \\
\hline $70: 30$ & 60 & $6463.33 \pm 15.10^{\mathrm{d}}$ & $65.69 \pm 0.29^{c}$ & $3.40 \pm 0.16^{\mathrm{c}}$ & $12.41 \pm 0.34^{\mathrm{c}}$ & $43.05 \pm 0.38^{\mathrm{d}}$ & $5.11 \pm 0.12^{\text {de }}$ & $16.97 \pm 0.35^{\mathrm{ab}}$ \\
\hline $70: 30$ & 72 & $7689.00 \pm 19.12^{b}$ & $66.48 \pm 0.36^{\mathrm{b}}$ & $2.57 \pm 0.17^{\mathrm{d}}$ & $10.89 \pm 0.21^{\mathrm{d}}$ & $43.40 \pm 0.40^{\mathrm{cd}}$ & $4.78 \pm 0.10^{\mathrm{e}}$ & $14.28 \pm 0.22^{\mathrm{d}}$ \\
\hline 60: 40 & 48 & $5228.33 \pm 12.37^{\mathrm{i}}$ & $62.64 \pm 0.19^{\mathrm{e}}$ & $4.10 \pm 0.21^{\mathrm{a}}$ & $15.48 \pm 0.10^{\mathrm{a}}$ & $39.37 \pm 0.36^{\mathrm{g}}$ & $7.25 \pm 0.18^{\mathrm{a}}$ & $17.50 \pm 0.47^{\mathrm{a}}$ \\
\hline 60: 40 & 60 & $5582.67 \pm 10.46^{\mathrm{g}}$ & $64.43 \pm 0.09^{d}$ & $3.69 \pm 0.34^{\mathrm{bc}}$ & $13.97 \pm 0.26^{\mathrm{b}}$ & $41.09 \pm 0.25^{\mathrm{f}}$ & $5.47 \pm 0.19^{c}$ & $17.13 \pm 0.28^{\mathrm{ab}}$ \\
\hline 60: 40 & 72 & $7775.67 \pm 18.18^{\mathrm{a}}$ & $66.92 \pm 0.08^{\mathrm{b}}$ & $3.65 \pm 0.20^{\mathrm{bc}}$ & $10.26 \pm 0.12^{\mathrm{f}}$ & $44.13 \pm 0.43^{\mathrm{bc}}$ & $3.61 \pm 0.16^{\mathrm{f}}$ & $13.61 \pm 0.40^{\mathrm{e}}$ \\
\hline CV (\%) & & 0.67 & 0.55 & 8.26 & 2.50 & 1.04 & 4.79 & 2.78 \\
\hline LSD & & 64.99 & 0.62 & 0.34 & 0.43 & 0.76 & 0.34 & 0.67 \\
\hline
\end{tabular}

Data: mean $\pm \mathrm{SD}$, means with the same letter in the column are not significantly different, QPM flour $=60,70$ and $80 \%$, teff flour $=20,30$ and $40 \%$, $\mathrm{L}^{*}=$ lightness, $\mathrm{a}^{*}=$ redness, $\mathrm{b}^{*}=$ yellowness.

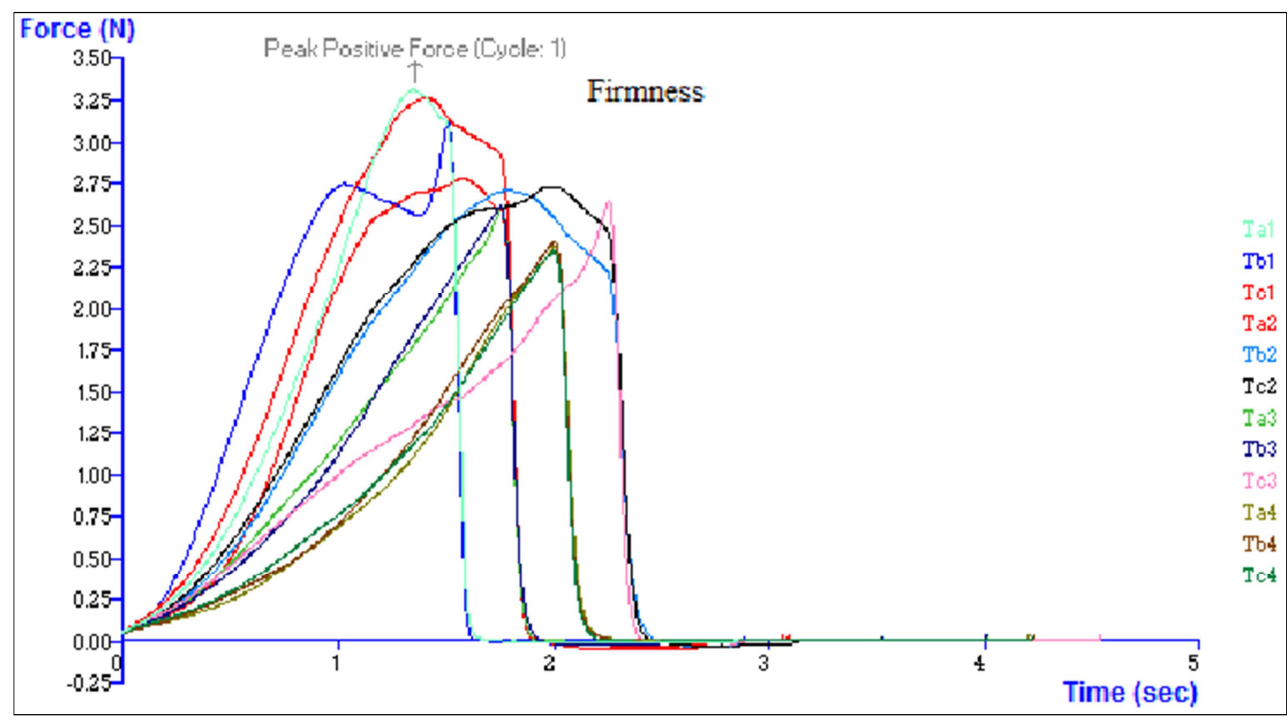

Figure 1. Firmness graph of QPM-teff composite injera samples fermented for $48 \mathrm{hr}$. 


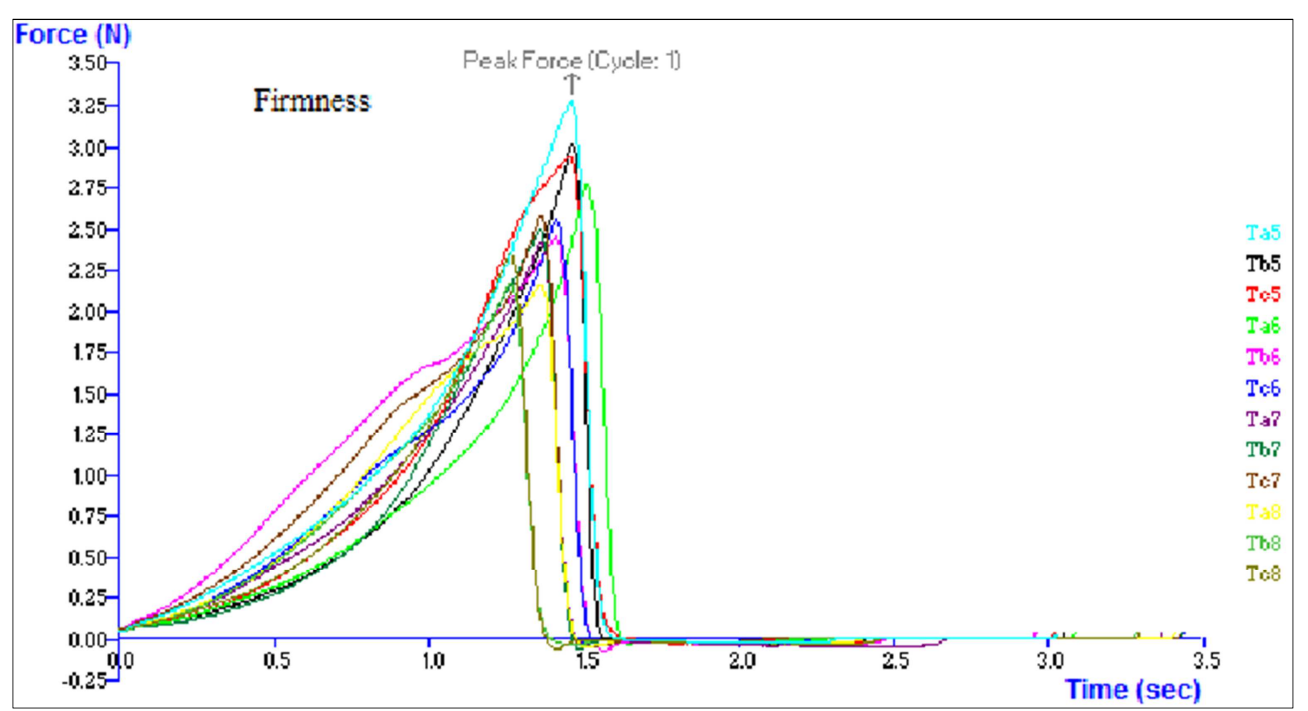

Figure 2. Firmness graph of QPM-teff composite injera samples fermented for $60 \mathrm{hr}$.

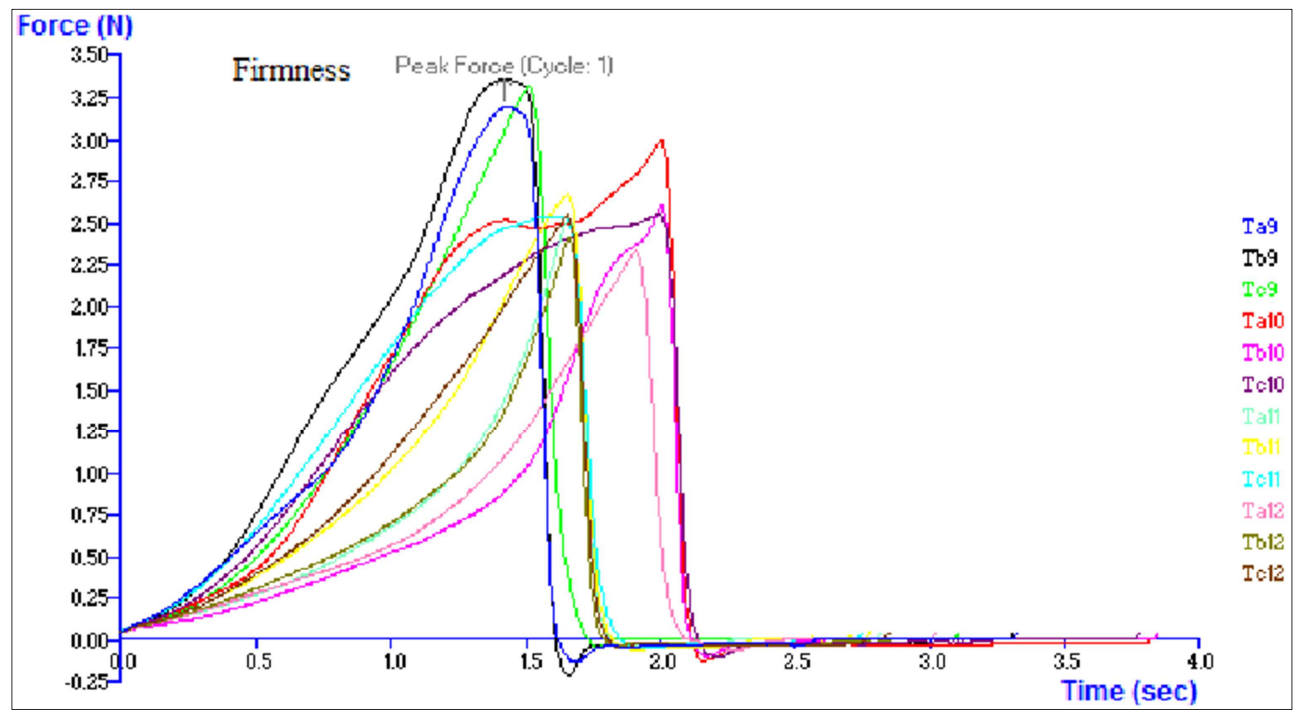

Figure 3. Firmness graph of QPM-teff composite injera samples fermented for $72 \mathrm{hr}$.

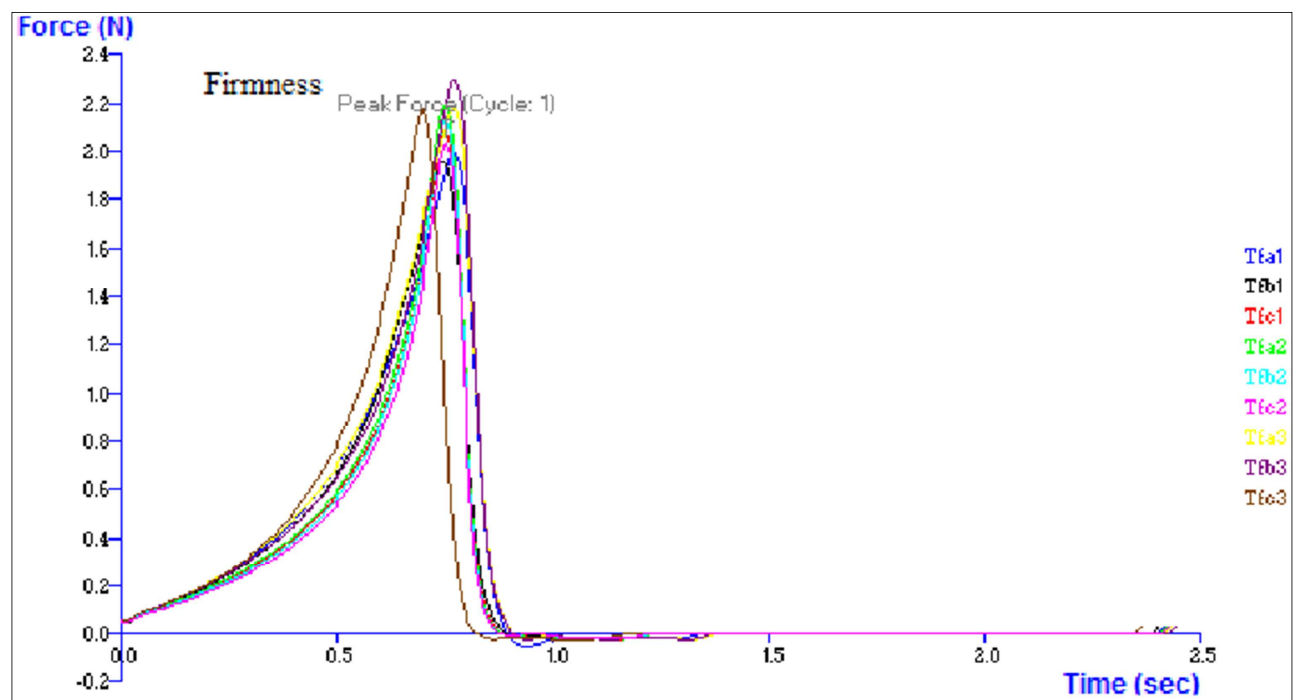

Figure 4. Firmness graph of teff injera samples. 


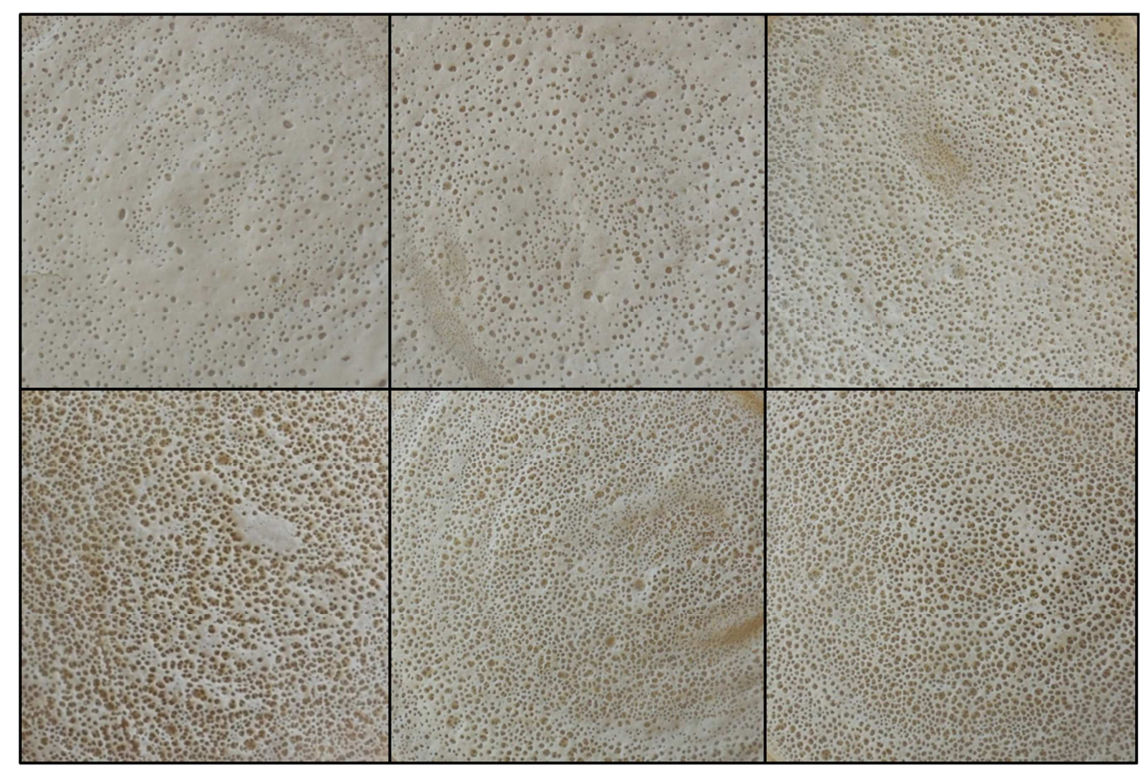

Figure 5. QPM-teff blended injera samples.

\section{Conclusions}

Quality protein maize is nutritionally enhanced variants of maize, and preparing injera from QPM has considerable advantages both nutritionally and economically over teff. However, injera prepared from QPM are only preferred in their fresh state and softness does not last as long as teff injera. Fermentation time is important factor that affects the eye qualities and distributions of injera. The study showed that, blending ratio of teff flour and fermentation times had significant effect $(\mathrm{p}<0.05)$ on the eye-size, texture, rollability, firmness, number of eyes and color (surface and hole) of injera. As the blending proportion of teff flour increased, better preference was observed for texture and rollability. Lower stalling and firmness were also observed with increasing in teff proportions.

\section{Acknowledgements}

The author is thankful to Mr. Mulate Zerihun (Food Science Laboratory, Melkassa Agricultural Research Center) and the staff of Melkassa Agricultural Research Center for their helpful contribution on the sensory work.

\section{References}

[1] Attuquayefio, W. D. (2014). Influence of processing parameters on eye size and elasticity of teff-based injera. Master's thesis: Pennsylvania State University.

[2] Bultosa, G., Hall, A. N., and Taylor, J. R. (2002). Physicochemical characterization of grain teff [Eragrostis teff (Zucc.) Trotter] starch. Starch/Stärke, 54 (10): 461-468.

[3] Goesaert, H., Brijs, K., Veraverbeke, W., Courtin, C., Gebruers, K., and Delcour, J. (2005). Wheat flour constituents: how they impact bread quality and how to impact their functionality. Trends in Food Science and Technology, 16 (1-

\section{3): $12-30$.}

[4] Hayelom, B. (2018). Influence of nitrogen fertilizer rates and varieties on grain yield, grain nutrition and injera sensory quality of teff [Eragrostis teff (Zucc.) Trotter] varieties. Master's thesis: Addis Ababa University.

[5] Kaleab, B., Claire, M. R., Christèle, I. V., Isabelle, R., and Jean-Pierre, G. (2013). Influence of flour blend composition on fermentation kinetics and phytate hydrolysis of sourdough used to make injera. Food Chemistry, 138: 430-436.

[6] Krivanek, A. F., De Groote, H., Gunaratna, N. S., Diallo, A. O., and Friesen, D. (2007). Breeding and disseminating quality protein maize (QPM) for Africa. Afr. J. Biotech., 6: 312-324.

[7] Mekonnen, M., Zarnkow, M., and Becker, T. (2014). Teff [Eragrostis teff (Zucc.) Trotter] as a raw material for malting, brewing and manufacturing of gluten-free foods and beverages: A review. J. Food Sci. Technol., 51 (11): 28812895 .

[8] Nuss, E. T., and Tanumihardjo, S. A. (2011). Quality Protein Maize for Africa: closing the protein inadequacy gap in vulnerable populations. Advances in Nutrition, 2: 217-222.

[9] Onyango, C., Unbehend, L., Unbehend, G., and Lindhauer, M. G. (2015). Rheological properties of wheat-maize dough and their relationship with the quality of bread treated with ascorbic acid and malzperle classic bread improver. African Journal of Food Science, 9 (2): 84-91.

[10] Senayit, Y., de Kock, H. L., Rooney, L. W., and Taylor, J. R. (2004). Effects of sorghum cultivar on injera quality. Cereal Chemistry, 81 (3): 314-321.

[11] Senayit, Y., Rooney, L. W., and Taylor, J. R. (2005). Improving the quality of sorghum injera by decortication and composting with teff. Journal of the Science of Food and Agriculture, 85: 1252-1258.

[12] Sofi, P. A., Wani, S. A., Rather, A. G., and Wani, S. H. (2009). Quality protein maize (QPM): Genetic manipulation for the nutritional fortification of maize. Journal of Plant Breeding and Crop Science, 1: 244-253. 
[13] Umer, A. (2019). Effect of blending ratio and natural fermentation time on the qualities of injera prepared from quality protein maize and teff flours. Master's thesis: Haramaya University.

[14] Weerasooriya, D. K., Bean, S. R., Yohannes, N., Ioerger, B. P., and Tesfaye, T. (2018). The effect of genotype and traditional food processing methods on invitro protein digestibility and micronutrient profile of sorghum cooked products. PLoS ONE, 13 (9), doi.org/10.1371/journa.pone.0203005.
[15] Yoseph, L. (2019). Process optimization and quality characterization of teff flour for the industrial manufacturing of injera. Doctoral thesis: Addis Ababa University.

[16] Zewdu, C., Gregory, R. Z., Habtamu, F., and Ashagrie, Z. (2018). Optimization and modeling of teff-maize-rice based formulation by simplex lattice mixture design for the preparation of brighter and acceptable injera. Cogent Food and Agriculture, 4: 1443381. 